\title{
El proyecto residencial colectivo en Chile. Formación y evolución de una política habitacional productiva centrada en la noción de copropiedad
}

\section{The collective residential project in Chile. Formation and evolution of a productive housing policy centered on the notion of Co-ownership}

\author{
Bustos Peñafiel Mónica (1)
}

\begin{abstract}
RESUMEN
La vivienda en altura regida bajo el concepto de copropiedad ha tenido una larga trayectoria en Chile. Sin embargo, aunque el concepto conlleva el valor de la vida comunitaria, se plantea que existiría una desconexión entre proyecto, copropiedad y modos de habitar, determinando diversas y complejas relaciones vecinales según el tipo de propuesta. Con el objetivo analizar cómo se ha establecido la relación entre el enfoque de la política pública y los resultados espaciales del proyecto residencial en altura, el articulo desarrolla un recorrido histórico, exponiendo las múltiples transformaciones tipológicas y espaciales que ha experimentado y su relación con la noción de copropiedad. Denominados en la actualidad como condominios sociales, se concluye que, su producción ha estado definida por un enfoque predominantemente económico, como es la eficiencia en el uso del suelo o el número de unidades habitacionales, lo que ha determinado la progresiva racionalización de los conjuntos, invisibilizando la noción de copropiedad en el tiempo.
\end{abstract}

Palabras clave: Copropiedad, Condominios sociales, Ley de copropiedad inmobiliaria, Vivienda colectiva en altura, Vivienda social en Chile.

\section{SUMMARY}

High-rise housing governed by the concept of co-ownership has had a long history in Chile. However, although the concept implies the value of community life, it is suggested that there would be a disconnection between the project, co-ownership and ways of living, bringing about diverse and complex neighborhood relationships according to the type of proposal. In order to analyze how the relationship between the public policy approach and the spatial results of the high-rise residential project has been established, the article develops a historical journey, exposing the multiple typological and spatial transformations that it has undergone and its relationship with the notion of co-ownership. Currently known as social condominiums, it is concluded that their production has been defined by a predominantly economic approach, such as efficiency in the use of the land or the number of housing units, which has determined the progressive rationalization of the projects, which, with time, has obscured the notion of co-ownership.

Keywords: Co-ownership, Social condominiums, Real estate co-ownership law, Collective housing in height, Social housing in Chile. 


\title{
RESUMO
}

\begin{abstract}
A habitação em arranha-céus regida pelo conceito de copropriedade tem uma longa história no Chile. Porém, embora o conceito implique o valor da vida em comunidade, sugere-se que haveria um descompasso entre o projeto, a copropriedade e as formas de viver, ocasionando relações de vizinhança diversas e complexas de acordo com o tipo de proposta. Com o objetivo de analisar como se estabeleceu a relação entre a abordagem das políticas públicas e os resultados espaciais do projeto residencial em altura, o artigo desenvolve um percurso histórico, expondo as múltiplas transformações tipológicas e espaciais por que passou e sua relação com a noção de co-propriedade. Atualmente conhecidos como condomínios sociais, conclui-se que sua produção tem sido definida por um enfoque predominantemente econômico, como a eficiência no uso do terreno ou o número de unidades habitacionais, o que tem determinado a progressiva racionalização dos conjuntos, tornando a noção de propriedade conjunta invisível no tempo.
\end{abstract}

Palavras-chave: Co-propriedade, Condomínios sociais, Lei de co-propriedade imobiliária, Habitação coletiva em altura, Habitação de interesse social no Chile.

La noción de copropiedad asociada a la producción habitacional se instala en Chile a mediados de la década del treinta, vinculada principalmente a la edificación en altura.

De la mano de los procesos de modernización que el país fue experimentando con fuerza desde principios del siglo XX, expresados a través del crecimiento demográfico, la expansión y diversificación de las estructuras urbanas, sociales y productivas de las ciudades, la aparición de la vivienda en altura como tipología del actuar público se puede explicar por dos causas. Por un lado, se puede asociar a una creciente demanda por acceso a la vivienda urbana, posicionando la vivienda en altura como mecanismo de disminuir el déficit habitacional. Por otro lado, está la creciente demanda por suelo urbano, que instala la necesidad comenzar a aumentar las densidades por medio de tipologías colectivas.

Aparecen así los primeros edificios que en varias plantas acogerán a múltiples familias y con ello la necesidad de regular la convivencia colectiva, lo que obliga que el Estado se vea en la exigencia de establecer un marco legal en torno al dominio de los bienes comunes y su relación frente a la propiedad privada marcando el inicio del modelo de administración en copropiedad chileno (Bustos, 2014a)

Influenciados por el pensamiento moderno de la época, comienzan a aparecer diversas propuestas residenciales en altura, que, diseñadas bajo un enfoque integral buscan conformar entornos de carácter colectivo por medio de una alta calidad proyectual de los espacios y bienes comunes al conjunto (Aguirre, 2011) determinando el inicio de un proceso de transformación morfológica del tejido urbano. Posteriormente, durante la década de los ochenta y los noventa, determinada por las bases de una política neoliberal que propició la construcción de vivienda pública en propiedad bajo un enfoque altamente mercantilista (Hidalgo, 2005; Ducci, 1997; Rodríguez y Sugranyes, 2005), se registra la más alta producción habitacional en altura desarrollada en el país hasta ese momento. Sin embargo, aunque se logra disminuir significativamente el déficit habitacional, la baja calidad arquitectónica y constructiva de las viviendas, el hacinamiento y la configuración de conjuntos carentes de consideraciones proyectuales y espaciales colectivas, se suma al desconocimiento de las familias en relación al significado de vivir en copropiedad, determinando un complejo cuadro de múltiples dimensiones, que poco a poco, fue degradando las condiciones de habitabilidad de sus residentes. 
Se instala de este modo la pregunta respecto de si es posible establecer una relación entre el enfoque de producción de la política pública y los resultados espaciales de la vivienda en altura, la configuración de los bienes comunes y las formas de convivencia vecinal. Esto nos lleva a plantear como hipótesis la idea de que en las diversas políticas habitacionales implementadas en Chile ha primado como tendencia un carácter altamente productivo, en el que las lógicas proyectuales de los conjuntos de vivienda social en altura no han tenido en consideración la noción de copropiedad asociada a las prácticas cotidianas de los habitantes, así como las formas de organización y convivencia vecinal.

Desde esta problemática, el articulo tiene como objetivo evidenciar cómo la evolución y consolidación del proyecto residencial colectivo ha estado determinada predominantemente por aspectos económicos como son la eficiencia en el uso del suelo, el número de unidades habitacionales o la regulación de los estándares de construcción, lo que ha llevado a la progresiva racionalización de los conjuntos por sobre la configuración de unidades de carácter colectivo, de adecuado tamaño y morfología, espacialmente reconocibles por sus habitantes o con una distinción clara de la propiedad privada respecto de los bienes comunes, entre otros aspectos. De este modo, si desde la construcción social del hábitat (Múnera y Sánchez, 2012; Yori, 2015) el concepto de copropiedad conlleva el valor de la vida en comunidad, el articulo da cuenta cómo desde las propuestas tipológicas y espaciales generadas por las políticas públicas, el sentido de lo colectivo se va invisibilizando en el tiempo de acuerdo a los distintos periodos estudiados.

Como un estudio de carácter histórico y descriptivo, la metodología propuesta fue abordada desde un exhaustivo trabajo de revisión bibliográfica, documental y fotográfico a nivel nacional. Desde una perspectiva integral y comparada en el tiempo, sobre la base del enfoque y la formulación de la política pública de acuerdo a cada contexto político, social y económico, el estudio analiza las diversas leyes y normas desarrolladas en cuanto a estándares de producción habitacional, así como en relación a las normas que van consolidando la noción de copropiedad como sistema de convivencia y administración de la vivienda en altura. Por medio del levantamiento fotográfico y la construcción de cartografías, se van identificando las distintas tipologías residenciales utilizadas por la política pública, así como las configuraciones morfológicas resultantes en cada periodo, reconstruyendo la transformación, evolución y configuración del proyecto residencial en altura en Chile asociado a la noción de copropiedad.

Si bien vale la pena relevar la construcción de vivienda pública como la expresión del quehacer del Estado a lo largo de más de cien años, analizar el dilema entre el déficit habitacional y las respuestas generadas desde la política pública desde un enfoque colectivo pasa a ser de alto interés, en tanto, reflejados en los diversos "modelos socio-tipológicos" (Bustos, 2005:127)2, fuertemente vinculados a la transformación morfológica del tejido urbano, podemos ver cómo, simultáneamente, se genera una representación socio-espacial en la ciudad, identificando proyectos residenciales carentes de una configuración que favorezca la vida en comunidad que finalmente, se constituyen en casos de alta marginalidad urbana.

El concepto de modelo socio-tipológico hace referencia a la formación de tipologías arquitectónicas y urbanas de carácter público que han aparecido como resultado del enfoque de la política habitacional impulsado, determinando la imagen urbana de la ciudad según su periodo en la construcción. 
Esta realidad, que hoy afecta a cientos de familias, la certeza de que existen intervenciones habitacionales de gran valor arquitectónico y urbano con un alto deterioro, así como la necesidad de indagar en nuevas morfologías residenciales colectivas, centran el interés del estudio en la vivienda en altura como tipología. Conscientes del actual contexto nacional de fuertes desigualdades urbanas, cada vez con nuevas y complejas exigencias (OCDE, 2013), teniendo presente que las ciudades ya no pueden seguir creciendo en extensión en términos de eficiencia funcional, económica y medioambiental, el estudio abre el debate en torno de la presencia y uso de la noción de copropiedad como fundamento esencial al proyecto residencial en altura de carácter público.

En este sentido, si bien se trata de una materia bastante especifica que hasta ahora prácticamente no ha sido explorada, los resultados dejan en evidencia la necesidad de pasar de una mirada de orden exclusivamente racional y productiva, a una que incorpore desde el diseño del proyecto residencial consideraciones respecto de la forma urbana y la configuración de los bienes comunes, así como aquellas referidas a las formas de convivencia vecinal, administración y mantención de los conjuntos, con el objetivo de favorecer la calidad de vida de los habitantes y su sostenibilidad en el tiempo.

\section{El habitar colectivo: del falansterio a la vivienda en altura}

Una de las primeras aproximaciones al proyecto residencial colectivo, está representada por los falansterios desarrollados por Charles Fourier a fines del siglo XIX sobre la base del socialismo utópico. Como un sistema organizado y autónomo para alojar un número reducido de obreros (de 1.200 a 1.600) a partir del uso común de inmuebles, servicios y equipamientos, los falansterios, además de responder a una necesidad de carácter funcional, vinieron a brindar un sentido refundacional a la sociedad y el territorio (Wiedenson, 1960). En Estados Unidos, esta concepción utópica se fundió en las denominadas company towns, que, como asentamientos productivos complementarios a los sistemas tradicionales "promovieron la producción de escala industrial sobre la base de una estricta jerarquía social, la dotación del bienestar para cada uno de los habitantes-obreros; y, el control del comportamiento de cada individuo" (Garcés, 2007:29).

Con la consolidación de la industria a principios del siglo XX, cuando la separación entre la vivienda y el trabajo termina por consumarse, se inicia una nueva fase de exploración en torno a las formas colectivas de habitar. Marcada por la fuerte migración campo ciudad y la fuerte expansión de las ciudades, aunque, en primera instancia se instala el debate en torno al estudio de nuevos modelos de crecimiento urbano, posteriormente este estará centrado en la búsqueda de innovación tipológica de la residencia masiva. Este hecho pasa a ser clave, en tanto, si en las primeras décadas del siglo los nuevos modelos de crecimiento urbano estaban sustentados en la idea de extensión propuesta con el modelo de Ciudad Jardín, a partir de los años veinte comienza a ser rechazado a cambio de un pensamiento que plantea como requerimiento a las ciudades la necesidad alcanzar mayores densidades.

Bajo este nuevo enfoque, el estudio de un tipo habitacional en densidad que permitiera la óptima utilización del suelo, la configuración de nuevas condiciones de la residencia, así como la economía de la edificación y el uso de nuevas tecnologías de producción, se instalan como temas centrales del debate en torno a la construcción de la ciudad moderna, posicionando la 
vivienda en altura como alternativa a la problemática del alojamiento masivo. Implantando una nueva cultura del habitar, con un nivel más elevado de sociabilidad, "el negocio inmobiliario pasa a convertirse en una actividad de primer orden que termina por sustituir masivamente la casa unifamiliar por la vivienda en altura propia de la ciudad industrial", (Martí, 2000:15), a partir de lo cual se configura una noción moderna de lo colectivo.

En este sentido, aunque la vivienda colectiva es pensada sobre las bases conceptuales de la producción en serie, para los urbanistas modernos -guiados por un razonar ontológico a partir de un discurso socialista y filantrópico de cambio-, su utilización se basa en la idea de una efectiva, equilibrada y pacífica convivencia comunitaria (Ballén, 2010). De aquí que, en el ámbito de lo colectivo, donde la individualidad está concentrada bajo el mismo y reducido contexto territorial, "los espacios considerados privados pierden importancia, y en su lugar, lo estimado como público, cobra relevancia como un catalizador que hace posible a la sociedad misma y, por consiguiente, a las ciudades" (Solo, 1987 en Ballén, 2010: 63).

Desde estos fundamentos, al analizar la historia y evolución de la vivienda colectiva, se puede constatar cómo desde sus primeras manifestaciones, su producción se desarrolla sobre la base del reconocimiento de la ciudad en el que la intensidad de servicios, cercanías y afinidades sociales son esenciales (Ballén, 2010) a la alta densidad. A nivel arquitectónico, esto se manifiesta a partir del uso del bloque como nueva tipología residencial sobre el cual se genera una estructura de servicios básicos comunes a un determinado número de habitantes. A nivel morfológico, esto implicará la ruptura de los viejos tejidos tradicionales, desencadenando en un nuevo tipo de trazado urbano, donde "el bloque o la configuración de una súper manzana compuesta por edificios residenciales colectivos pasa a ser el elemento constitutivo propio de la ciudad moderna" (Martí, 2000:15), resultado de la búsqueda de una estrecha y equilibrada relación entre la edificación y el espacio libre, entre vacío y lleno, público y privado. En este sentido, aunque este equilibrio comenzará a diluirse a causa de los procesos especulativos que acompañan la formación de la ciudad industrial, en las propuestas residenciales de la cultura moderna los temas característicos de la tradición urbana como la calle, la plaza o la manzana, en su condición de arquetipos siguen siendo utilizados y reinterpretados (Martí, 2000).

\section{Vivienda colectiva y configuración del entorno inmediato como un bien común}

Entendido como un territorio semi-público o semi-privado, en el que establece la posibilidad de interacción entre los miembros de un grupo no muy numeroso de familias vecinas compartiendo un lugar común, el entorno inmediato pasa a configurar lo que ha sido denominado como el mesosistema, donde la vivienda como la unidad básica es el microsistema y el barrio pasa a constituirse en el macrosistema (Haramoto, 1990).

Como un espacio intermedio de proximidad entre el espacio privado y el barrio, el entorno inmediato pasa a ser el hábitat sobre el cual las prácticas cambiantes, la reorganización y reinterpretación del espacio físico "vuelven a dibujar continuamente las fronteras entre lo público y lo privado (Crawford, 1995 en Salcedo, et al., 2017:179). Es por ello que, el entorno inmediato no se puede concebir como algo dado, "como un objeto con existencia propia e independiente de los sujetos. Por el contrario, el hábitat y las formas de habitar humano se construyen, de-construyen 
y re-construyen permanentemente; [...] a partir de la interacción de individuos y grupos humanos diversos" (Múnera y Sánchez, 2012:77) de acuerdo a un determinado contexto cultural, social y económico que influye en las formas de habitar.

Desde este enfoque, si entendemos el entorno inmediato como el soporte de la vivienda social en altura, este adquiere especial relevancia como el espacio representativo de la vida en comunidad, el bien común en el que conviven un número de habitantes quienes establecen su apropiación por medio del uso, la interacción entre vecinos, el cuidado y la mantención de dichos espacios, aunque esta no siempre sea positiva. Por ello, la complejidad que reviste la adecuada configuración física y espacial del entorno inmediato para la vivienda colectiva pasa a ser fundamental, en tanto "vivir en comunidad es vivir en una sociedad donde sus miembros se conocen y confían mutuamente entre sí, comparten vida cotidiana y trabajo y desarrollan su actividad teniendo como fondo un paisaje al que aman" (Delgado, 2008:1). Para Santos (2000 en Hernández 2001) en este sentido, el carácter material de los territorios implica una dimensión ontológica que alude principalmente, a las representaciones humanas asociadas a las vivencias individuales y sus implicancias. Es por ello que, aspectos como la identidad y el arraigo de los habitantes con los lugares que habitan, resultan claves a la hora de comprender los territorios.

Atendiendo a las implicancias que tiene la producción del espacio como una construcción social, es que resulte imprescindible en materia de vivienda colectiva, tener en consideración la adecuada configuración del entorno inmediato a partir de la identificación de los elementos estructurantes de la edificación y de las propias dinámicas. Es decir, configurando desde el diseño el territorio de la copropiedad como unidad administrativa de quienes la habitan, comprendiendo "los estilos de vida de sus residentes, el tipo de control que ejercen sobre su entorno inmediato, y el tipo de relaciones sociales que existe entre ellos" (Salcedo, 2010:171).

\section{La vivienda en altura como tipología de carácter colectivo y la formación del concepto de bien común}

Las necesidades residenciales del siglo XX están marcadas por el declive del patrón económico exportador del siglo XIX, que tiene como contexto la primera guerra mundial y la crisis del capitalismo de la década de 1930, a partir de lo cual se crean las condiciones que reemplaza la producción primaria de exportación por una política de sustitución de importaciones dirigida al mercado interno como nuevo modelo de desarrollo económico (Bravo y Martínez, 1993). Se impulsa así, un proceso sostenido de industrialización que determinará la concentración de la población en distintos centros urbanos, configurando un cuadro de alta informalidad.

Esta realidad, otorga relevancia crítica a la dimensión política del problema del déficit habitacional, posicionando al Estado como garante de las condiciones físico-poblacionales para la reproducción de la fuerza de trabajo (Raposo, 2001). En este contexto, con el desafío de masificar la construcción habitacional, se crea en 1936 la Caja de Habitación Popular y posteriormente, la Caja de la Habitación en 1943, institucionalizando por primera vez a través de un organismo del Estado, las disposiciones que obligan a la construcción de barrios obreros (Valenzuela, 2007). 
Figura 1.

Ley de venta por pisos, 1937.

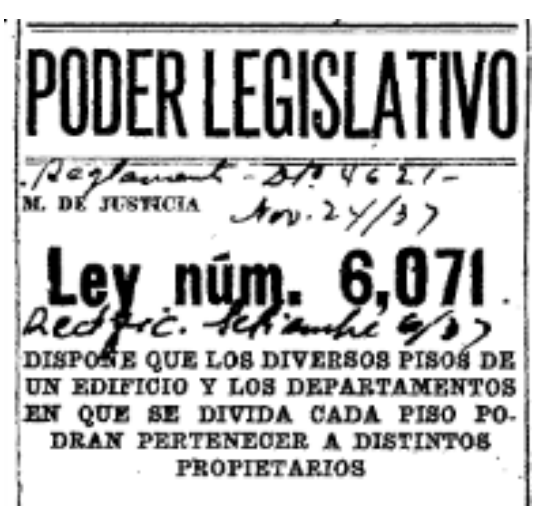

Fuente: Diario Oficial, 1937.

Se instala así, la vivienda colectiva en altura como nueva tipología representativa del actuar público, a partir de lo cual en 1937 se implementa la Ley № 6.071 de Venta por Pisos (Ministerio de Justicia, 1937), posibilitando desde ese momento que los edificios de dos o más pisos puedan pertenecer a distintos propietarios (Figura 1). La nueva ley establecerá un sistema reglamentario respecto de la convivencia y la vida comunitaria de los habitantes, el cuidado y la mantención de los bienes y espacios comunes de la edificación, así como la obligatoriedad de contar con una administración y un reglamento que garantice los derechos y deberes frente a un sistema de bienes comunitarios, instalando por primera vez en Chile la noción de copropiedad asociada a la corresponsabilidad que supondrá la formación de una comunidad funcional.

Paralelamente a este contexto de discusión y transformaciones, en un periodo de normalización de toda edificación, se instala la necesidad de establecer los criterios y estándares para la construcción habitacional pública y la provisión de equipamientos. De este modo, se implementa en 1936 la primera Ley General Sobre Construcciones y Urbanización y, posteriormente en 1944, la Ordenanza de Urbanización y Construcciones Económicas, constituyendo la base normativa sobre la cual se comienzan a configurar las primeras tipologías de vivienda pública de la época.

Aunque el marco regulatorio para la edificación habitacional económica va asociado a la necesidad de considerar un alto grado de estandarización e industrialización de la producción a través de nuevas técnicas constructivas, con el objetivo de desarrollar propuestas higiénicas e integradas al contexto de la ciudad, se establecerán también nuevos principios respecto a los sistemas de agregación, ordenamiento, distanciamiento, ventilación, soleamiento, privacidad, conexión con la calle, así como respecto a la incorporación de distintos tipos de espacios colectivos como servicios, equipamientos y áreas verdes, etc. lo que dará paso hacia el cambio morfológico del tejido urbano fundacional. Influenciados por las ideas del movimiento moderno, bajo una concepción racional pero también integral de las propuestas, la vivienda se convierte en un símbolo de modernización social, económica y tecnológica (Aguirre, 2011).

En este sentido, aunque no se establecen consideraciones especificas respecto de la configuración física y espacial de las copropiedades, el uso del bloque como nueva tipología (Figura 
$\left.N^{\circ} 2\right)$, de la mano de inéditas formas de emplazamiento y posibilidades de combinación con otras tipologías, marcan el inicio de la ruptura interior de la manzana (Figura $\mathrm{N}^{\circ} 3$ ), permitiendo con ello la formación de espacios intermedios de carácter colectivo como nuevo concepto urbano. En consecuencia, contenidos por la disposición de la edificación que aún respeta la trama urbana tradicional como soporte, a partir de ese momento se comienza a configurar una nueva calidad espacial de carácter intermedio y semipúblico (Bustos, 2014a), que se constituirá en el entorno inmediato de sus habitantes. Localizados estratégicamente para servir de transición entre la residencia y la vida urbana exterior, "Ios nuevos espacios pasan a convertirse en nuevos sistemas de distribución y nuevos atributos del sistema de parcelación, en el que la vivienda trasciende los límites de la habitación, y configura una imagen colectiva de vida moderna" (Valenzuela, 2007), lo que reforzará la noción de comunidad no sólo funcional, sino que, asociada a un espacio de uso colectivo. De este modo, "si antes la parcela era exclusivamente para uso y beneficio privado, desde ahora se relativiza agregando un nuevo valor en el mercado inmobiliario: el espacio colectivo" (Valenzuela, 2007: 83).

Figuras 2 y 3 .

Colectivo Lord Cochrane. Caja de la Habitación. Santiago, 1941.
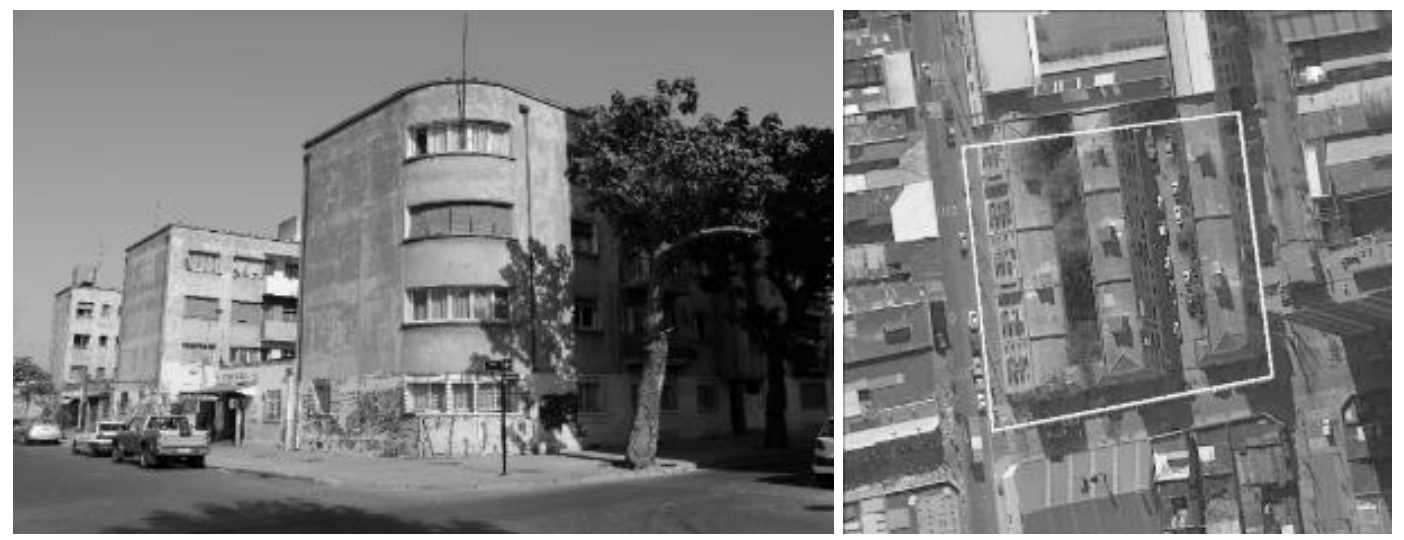

Fuente: Elaboración Propia y Google Earth.

\section{La racionalización de la producción habitacional y el perfeccionamiento del marco legal de la copropiedad}

Como consecuencia de la más alta explosión demográfica del siglo XX y el significativo aumento de la informalidad urbana, en el año 1953 se crea la Corporación de Vivienda (CORVI) con el objetivo de consolidar una institucionalidad centrada en la producción habitacional para los sectores de bajos y medianos ingresos. Sus labores estarán centradas en la construcción directa para las Cajas de Trabajadores, la generación de incentivos tributarios para constructoras y compradores y el apoyo a la autoconstrucción con una urbanización mínima (Raposo, 2001).

Sobre la base que la industria de la construcción es un mecanismo de reactivación y crecimiento económico, se comienzan a implementar diversas estrategias para fomentar y racionalizar la producción habitacional, a través de una serie de políticas, leyes, planes y programas. Un hecho 
fundamental en este sentido es la implementación del DFL No 2 de 1959³ , que, con el objetivo de impulsar una fuerte racionalización de la producción, establecerá el marco normativo para toda construcción de vivienda pública. Asociado a un reglamento especial, a partir del nuevo decreto se definirán los estándares habitacionales en relación al emplazamiento y urbanización de los conjuntos, las características técnicas de la construcción, así como respecto del programa, superficie y mínimos de habitabilidad, de la que comienza a ser denominada vivienda económica.

Sin embargo, con una alta influencia de los principios del urbanismo moderno, por medio de la formulación de planes maestros, basados sobre un enfoque no solo habitacional, sino que también con una alta fundamentación urbana, las nuevas propuestas residenciales comienzan a incorporar distintos tipos de espacios colectivos como equipamientos y áreas verdes, (Raposo, 1999). Incorporando el uso bloque aislado rodeado de extensas áreas libres, es que se consolida definitivamente la edificación vertical como tipología de vivienda masiva, configurando una nueva morfología urbana de carácter abierto que terminará con la ruptura definitiva del trazado tradicional (Figura 4 y 5 ).

Figuras 4 y 5 .

Población Juan Antonio Ríos. Independencia, 1945-1959
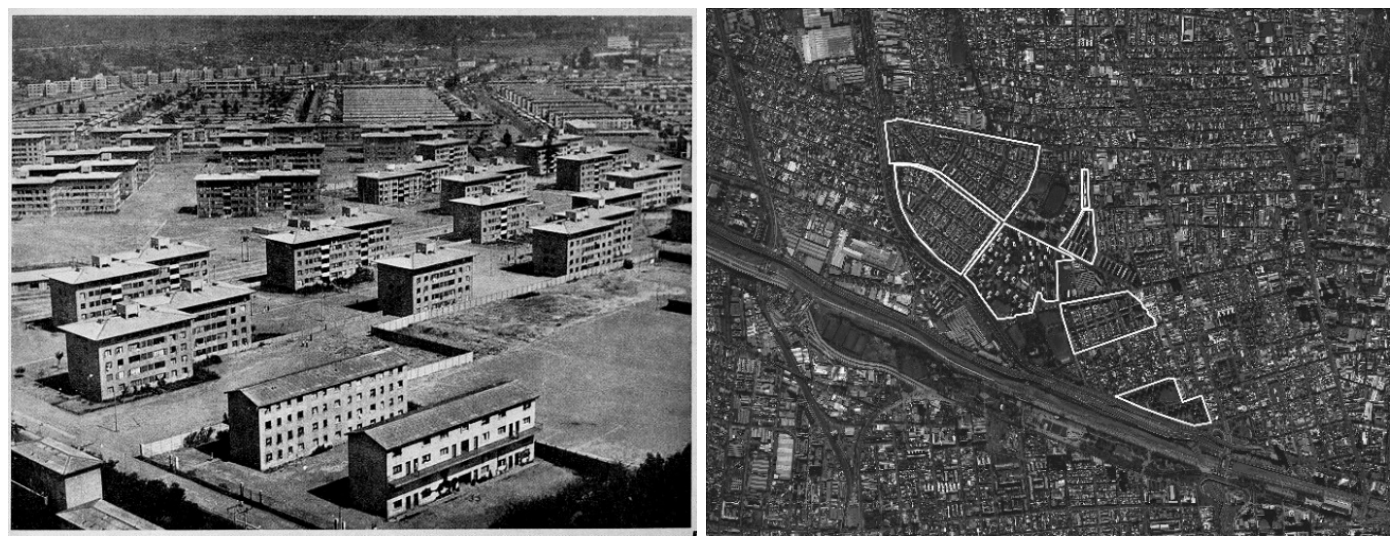

Fuente: Archivo MINVU y elaboración propia en base a Google Earth

En el marco de la copropiedad, uno de los hechos más significativos que evidencia la importancia de regular la fuerte producción habitacional en altura, es la incorporación, en 1963, de la Ley de Venta por Pisos a la Ley General de Construcciones y Urbanización. Formulando un quinto capítulo denominado "de la venta por pisos", la ley se transforma así en un instrumento normativo que incorpora simultáneamente a su construcción regulaciones específicas para todo edificio de vivienda colectiva.

El nuevo capítulo, pone énfasis en las formas de convivencia, uso, administración y mantención de los bienes y espacios comunes de varios propietarios dentro de un mismo edificio, estableciendo como exigencia la formulación de un reglamento de Copropiedad. De este modo,

El DFL N² 2 define la vivienda económica como aquella "que tiene una superficie máxima de 140 m²", promoviendo la construcción habitacional masiva mediante la aplicación de franquicias tributarias para las empresas constructoras como para los compradores. 
se comienza a forjar con más fuerza la noción de copropiedad, formalizando la necesidad de concebir la edificación no sólo para la residencia familiar, sino que, también configurando una comunidad en torno a los espacios compartidos, hecho que releva la importancia que se da en ese momento al vínculo entre la tipológica en altura con la copropiedad.

\section{Figura 6.}

Población San Joaquín Poniente. Colectivos 1002, 1006, 1007. CORVI. 1959

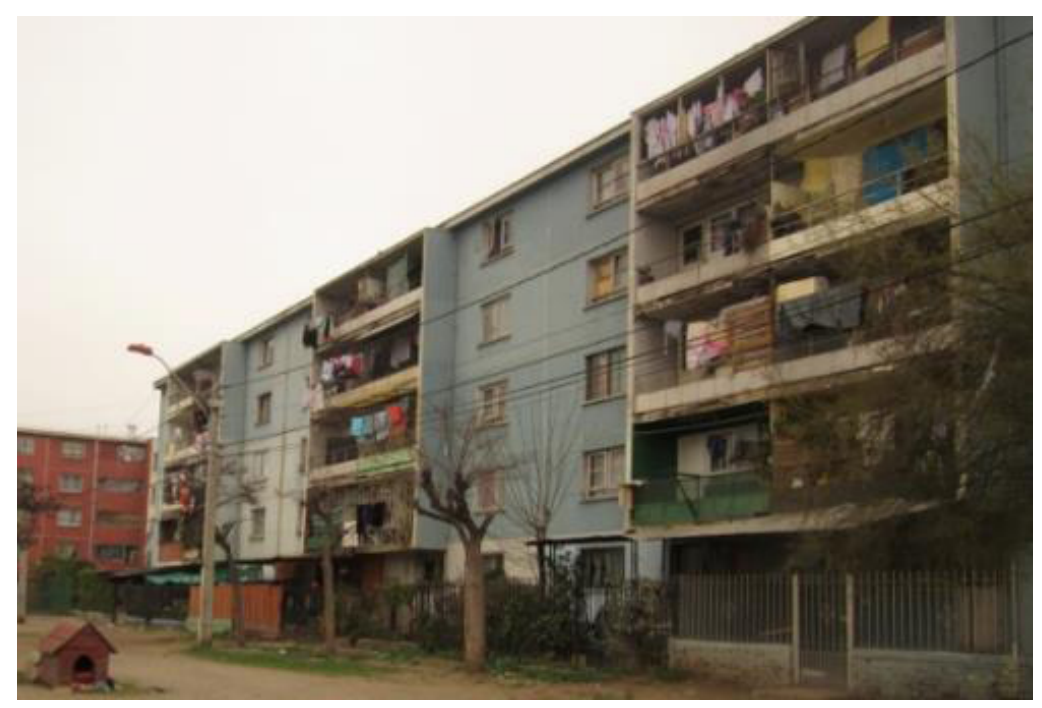

Fuente: Elaboración propia.

En un contexto marcado por "la formulación y puesta en marcha de políticas de desarrollo nacional" (Minvu, 2007:128), impulsadas a partir de la cooperación entre Estados Unidos y los países Latinoamericanos a través de la denominada "Alianza para el Progreso", en el año 1965 se crea el Ministerio de Vivienda y Urbanismo MINVU, con el objetivo de responder a la problemática habitacional "manteniendo la actividad económica, [...] y acrecentar la integración institucional de los marginales urbanos" (Espinoza, 1998:76 en Minvu, 2007:129).

Una de las herramientas claves para este objetivo fue el Plan de Ahorro Popular, a través del cual la vivienda en altura se masificará como tipología para las capas medias (Minvu, 2007). De la mano de la copropiedad como modelo de administración, en 1965 se aprueba el "Reglamento de Venta por Pisos o Departamentos de los Edificios de la Corporación de Vivienda", constituyéndose en un instrumento referido específicamente a la vivienda en altura realizada por la CORVI. En 1971, con el objetivo de organizar a las comunidades que habitan en los nuevos conjuntos, se actualiza nuevamente la Ley de Venta por Pisos, estableciendo nuevas obligaciones y atribuciones en torno a la administración como son: el cuidado de los bienes y servicios comunes, el cobro de las expensas para la mantención y hacer cumplir la Ley y el Reglamento de Copropiedad.

Sin embargo, con el significativo aumento de las edificaciones en altura se comienza a dificultar la fiscalización por parte del Estado en relación al cumplimiento de las exigencias establecidas en el reglamento, dejando en evidencia la complejidad que conlleva constituir las asambleas de copropietarios, y con ello, la incapacidad de mantención y administración de las copropiedades. 
Esta realidad se puede atribuir a que los conjuntos habitualmente no son inscritos en el Conservador de Bienes Raíces como un hecho formal que define jurídicamente la propiedad del suelo y la configuración de las copropiedades. Situación que se complejiza aún más, como consecuencia de la propia morfología del proyecto residencial, que, diseñado bajo los principios del movimiento moderno, dispone las unidades residenciales, equipamientos y áreas colectivas en grandes paños de terreno que en general no cuentan con límites administrativos claramente definidos. Sumado a lo anterior, otra situación clave se puede atribuir al significativo número de propietarios en conjuntos de gran escala, en los que en general no se fue considerada espacial ni jurídicamente la configuración de sectores o unidades menores de referencia (copropiedades), dificultando la organización para la administración y mantención de los bienes comunes (Bustos, 2014b).

Figura 7.

Población La Faena. Peñalolén, 1971. Colectivos 1010/1020/ 1040.

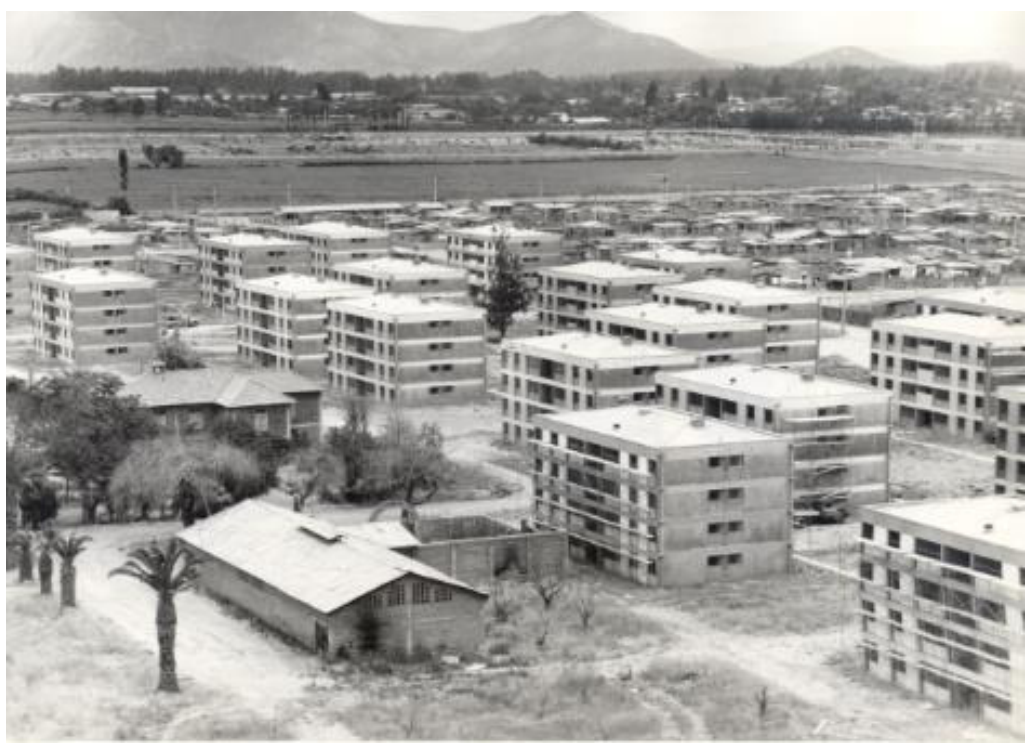

Fuente: Archivo MINVU

\section{La consolidación de un mercado de vivienda social y la masificación de bloques en altura:}

A partir del año 1973, en el marco de la dictadura militar se inicia en Chile un cambio ideológico hacia el libre mercado como modelo. Basado en un nuevo enfoque de la economía, se instaura así un importante proceso liberalizador de las actividades productivas, "transfiriendo al mercado y a la iniciativa privada la provisión de los bienes y servicios sociales" (Hidalgo, 2005:349) que tradicionalmente eran responsabilidad del Estado.

De este modo, la política habitacional sienta las bases de un nuevo sistema de financiamiento y producción, que, basado en el subsidio a la demanda, complementado con el crédito y el ahorro de las familias, centra su quehacer en solucionar el déficit básicamente por la vía cuantitativa, pri- 
vada y de bajo costo (Hidalgo, Zunino y Álvarez, 2007), a través de una vivienda de carácter propio y definitivo para la población de bajos más ingresos. Se genera así un escenario de confianza económica en el que la empresa privada, que usualmente había desarrollado sus proyectos para los sectores de altos y medianos ingresos, amplía su giro hacia la construcción masiva de viviendas sociales, consolidando una política cuyo fundamento se basa en una producción de mercado.

De manera paralela a esta nueva lógica de producción, la implementación de la Política Nacional de Desarrollo Urbano (DS N 420 V. y U.) de 1979, condicionará la localización periférica del nuevo y masivo parque habitacional. Bajo un nuevo concepto de crecimiento urbano, basado en la idea de expansión, la nueva Política deroga las densidades establecidas, otorgando al mercado la asignación de los usos de suelo sin intervención estatal, sino que definido por su mayor rentabilidad (Rodríguez e Icaza, 1993).

Todos estos factores, determinan que durante la década de los ochenta y particularmente durante la década los años noventa, la propia política habitacional termina por configurar "una "morfología social" donde persiste la polarización social y la segregación y, una morfología territorial en la que impera la suburbanización, la periurbanización y la policentralidad" (De Mattos, 2002:32).

En consecuencia, ausente de toda planificación o visión del crecimiento urbano y una clara concentración de los sectores de más bajos ingresos, por medio de "procesos de acabado urbano desfasados" (Bustos, 2005:217), se configura una nueva morfología del tejido residencial, de carácter homogéneo, localización periférica y deficiente accesibilidad a equipamientos y servicios.

Condicionados por factores de carácter económico que apuntan a una extrema racionalización del proyecto residencial, los distintos componentes a considerar en el diseño de la que comienza a ser denominada como "vivienda Social" ${ }^{4}$, son trabajados según los nuevos estándares establecidos en el "método de condicionantes mínimas" (MCM), según el cual:

“La selección y adjudicación [...] se realiza en función del menor precio en promedio de las viviendas ofertadas, las cuales deben cumplir con las Especificaciones Técnicas Mínimas [...]. La superación de estas exigencias [...] no implica una mejor calificación de las ofertas ya que el objetivo fundamental de este nuevo sistema es la obtención de la mayor cantidad de viviendas con los recursos disponibles" (MINVU, 1984:18)

Basado en dos variables fundamentales como son alcanzar el mejor aprovechamiento de los recursos económicos disponibles y la mejor utilización del recurso suelo, el diseño del conjunto, la arquitectura de la vivienda y los materiales básicos de construcción pasan a ser los factores que comienzan a configurar lo que será la morfología e imagen del proyecto residencial de este periodo.

\footnotetext{
En el marco del programa de vivienda básica se establece el Decretos Supremo DS168 de 1984 se define la vivienda social como aquella "vivienda económica" de carácter definitivo, financiada con recursos públicos y privados, cuyo valor de tasación no sea superior a 400 UF y cuyas características técnicas y de urbanización se ajusten a las normas generales de este reglamento.
} 
Con bajos estándares de construcción y un reducido tamaño de las viviendas, compitiendo respecto de lo que se había desarrollado previamente "en cuanto a nuevas tecnologías de construcción más industrializadas, con diseños sujetos a modulación y alternativas de prefabricación" (Bravo y Martínez, 1983:27), a nivel arquitectónico, aparece el uso bloque en 3, 4 o 5 plantas como una de las tipologías que caracterizará la incorporación del sector privado. Sin embargo, bajo una lógica de máxima utilización del suelo, por medio de un ejercicio repetitivo en la organización y distribución de los bloques, donde "es muy difícil encontrar alguna característica física espacial o social que permita diferenciarlos" (Segovia, 2010:80), a nivel morfológico, la configuración de los conjuntos se desarrollará homogéneamente sin una clara jerarquización de las áreas verdes o del equipamiento comunitario que sirva de referencia a los habitantes (Figura 8).

Figura 8.

Morfología de las áreas residenciales en base a bloques de vivienda en altura. Villa El Algarrobo.

Rancagua. 1992.

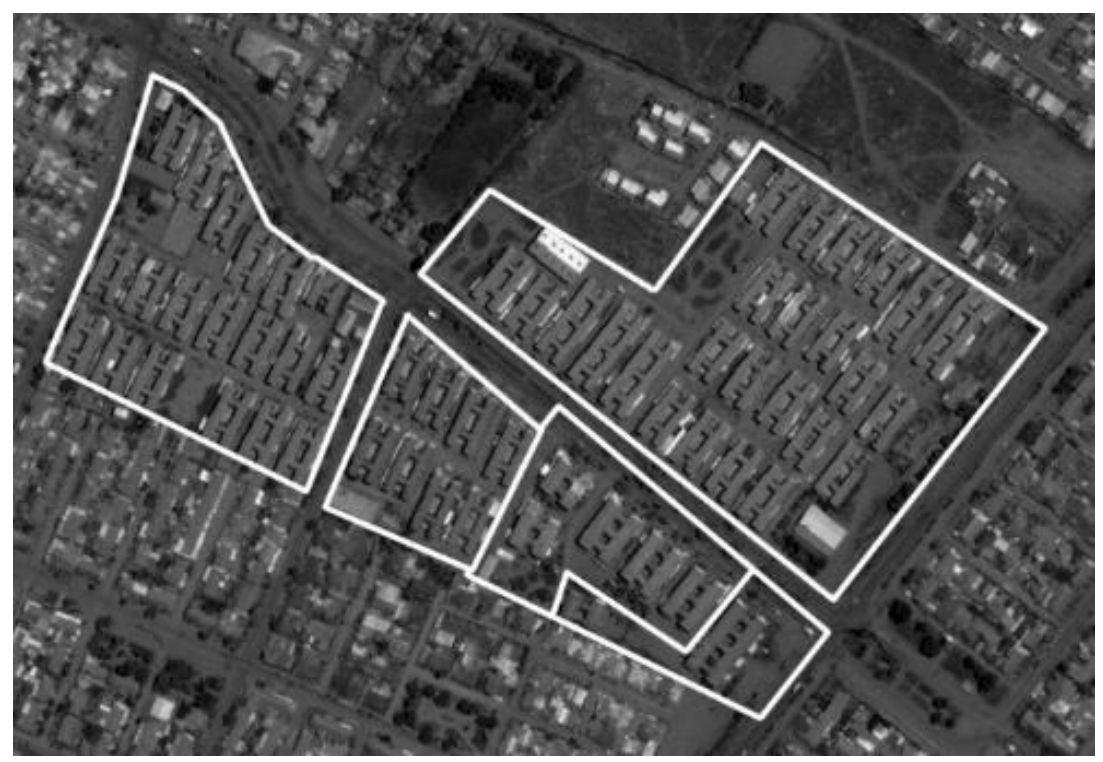

Fuente: Elaboración propia en base a Google Earth

\section{La invisibilización de la noción de copropiedad y la pérdida del sentido de lo colectivo.}

Tal como señalan Salcedo, Rasse y Cortés (2013:193), una característica común que presentan los habitantes al momento de llegar a vivir a un conjunto de vivienda social es que el sueño de la casa propia "viene acompañado de la ilusión de un barrio por el que se estaba dispuesto a trabajar colectivamente", iniciando un proceso de formación y fortalecimiento de un capital social que se verá reflejado en la formación de organizaciones sociales, y en la realización de una serie de actividades y celebraciones en las que los vecinos crean lazos de confianza y reciprocidad.

Sin embargo, como efecto de una política habitacional mercantilista, si bien en algunos casos las relaciones vecinales, la organización social y la solidaridad se logran sostener en el tiempo, por el paso de los años y las condiciones de adversidad que deben enfrentar a diario las familias, 
en la mayoría de los casos éstas se fueron debilitando, determinadas por diversas situaciones que comienzan a aparecer producto de la baja calidad de los conjuntos, la compleja convivencia vecinal en edificaciones colectivas de alta densidad y la falta de herramientas que favorecieran la organización social.

Esta problemática se complejiza aún más, como consecuencia del régimen de copropiedad bajo el cual deben ser administrados los conjuntos, constituyéndose en un elemento clave que fue potenciando negativamente el deterioro y el conflicto vecinal. Según lo establecido por la Ley de Venta por Pisos vigente hasta 1997, todos los bienes comunes edificados, como las áreas libres dispuestas entre bloques, son de carácter privado y administración colectiva por parte de copropietarios. Sin embargo, la masividad con que se fue construyendo la gran cantidad de vivienda social en altura, la ausencia de participación en la gestión de acceso a la vivienda, el gran número de erradicaciones, constituyendo conjuntos con familias de distintas procedencias sin haber tenido ningún tipo de vínculo previo (como pertenecer a alguna entidad o haberse organizado en un comité), determinaron la formación de un complejo contexto que, en muchos casos, no permitió consolidar un tejido social que favoreciera el sentido de comunidad.

Esta situación se ve agravada por la condición económica vulnerable de vecinos y copropietarios, compuestos también por un alto número de arrendatarios, quienes en la medida que no logran ser integrados, no muestran interés por el cuidado de aquello que no sienten como propio. En consecuencia, además de adaptarse a un departamento de mínima superficie, los habitantes debieron integrarse a un nuevo sistema de convivencia colectivo, sin embargo, la dispersa procedencia de las familias y los bajos niveles de identidad de los habitantes con su entorno fueron dificultando la asociatividad formal e informal, configurando en la mayoría de los casos precarias e inestables formas de acción colectiva, en torno al cuidado de los bienes y espacios comunes.

Figura 9 y 10.

Espacios comunes intervenidos a partir de las acciones de los habitantes. Población Lo Sierra. Comuna de Lo Espejo.
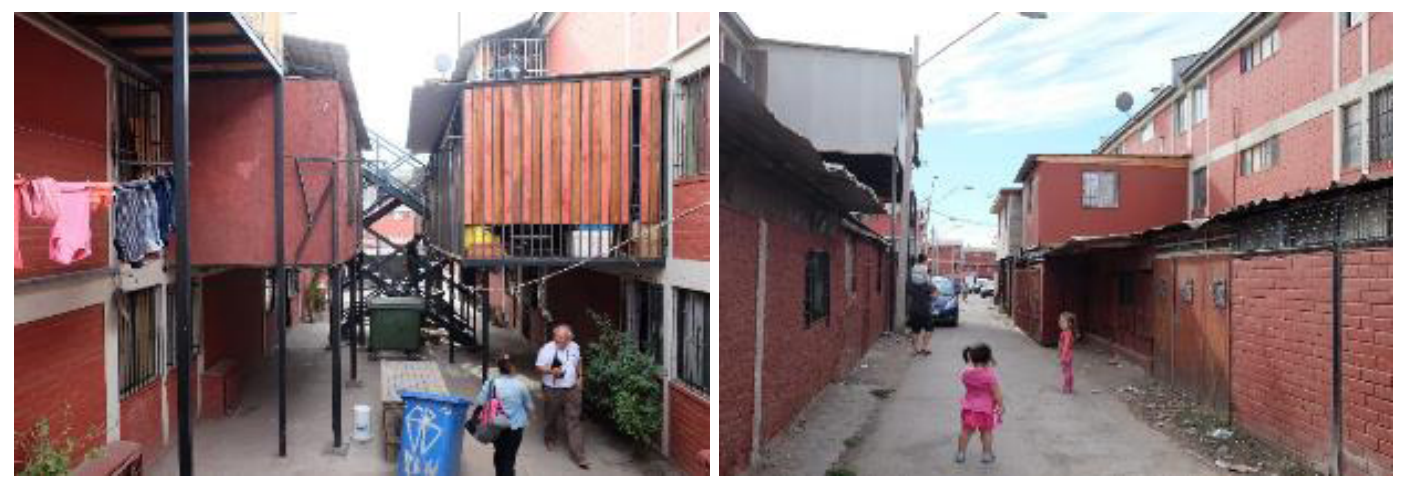

Fuente: Elaboración propia.

De este modo, de la mano del deterioro físico se va generando un deterioro social con profundas dificultades de convivencia. Esto provocó, que muchos de los habitantes frente a la vida cotidiana fueran resolviendo algunas de sus necesidades de forma autónoma, ampliando irre- 
gularmente sus viviendas, enrejando departamentos, pasillos y espacios comunes, entre otras acciones, lo que afectó finalmente la calidad de los entornos, la estructura de los bloques, y el abandono de bienes comunes que no sienten propios (Figura 9 y 10). Así también, condicionados por el hacinamiento o la ausencia de espacios comunes bien configurados, esta realidad provocó que muchas de las actividades cotidianas de los habitantes como son la tenencia de animales, la limpieza del hogar, el lavado de ropa, el juego de los niños o las celebraciones, por mencionar algunos ejemplos, se transformen en eventuales motivos de conflicto.

Esta realidad, sumada al desconocimiento por parte de las familias acerca del significado de vivir bajo el régimen de comunidad de copropietarios, la falta de herramientas respecto a la administración de los bienes comunes y los bajos niveles de educación, han afectado aún más las capacidades de organizarse y autogestionar sus bienes comunes, configurando un cuadro de progresiva y acelerada tendencia al deterioro. Marcados además por el aislamiento y la concentración de la pobreza, muchos de los conjuntos se fueron transformando en territorios estigmatizados en los que las problemáticas de la segregación fueron mutando, desde sectores desfavorecidos en cuanto a su localización, aislados y sin equipamiento, a sectores con microtráfico, xenofobia, violencia, hacinamiento (Sabatini, F., et. al, 2013) lo que ha derivado en un alto nivel de insatisfacción y la pérdida de un sentido de pertenencia e identidad de los habitantes respecto a sus barrios.

En consecuencia, según señalan Rodríguez y Sugranyes (2010), respecto a la intención de movilidad que sienten los residentes de viviendas sociales distribuidas según tipología, existe aún mayor intención de salir de las viviendas en copropiedad que de los lotes individuales (70\% y 55\%, respectivamente), lo que es un claro reflejo de la relación que se establece entre los problemas de satisfacción y el espacio físico habitado.

\section{Reconocimiento de la copropiedad en el diseño e implementación de la política habitacional}

Según el Catastro Nacional de Condominios Sociales (MINVU, 2014), durante la década del ochenta y especialmente del noventa, nuestro país construyó la mayor cantidad de viviendas sociales en altura de su historia, registrando entre 1979 y 1999 un peak, con la construcción del $48,61 \%$ de departamentos de las 344.403 unidades totales registradas a lo largo de la historia.

Aunque las cifras demuestran la efectividad que tuvo la política habitacional de subsidios implementadas durante estos años, el impacto social y urbano de esta producción fue tan alto, que desencadena en la formulación de la "Política habitacional de mejoramiento de la calidad e integración social" (MINVU, 2006), poniendo foco desde ahora solo en la disminución del déficit habitacional, sino que también en el mejoramiento de los barrios y viviendas ya construidos.

En materia de producción habitacional, a partir de una lógica que modifica los mecanismos de financiamiento, se genera, entre otros aspectos, un cambio normativo que busca mejorar la calidad constructiva y espacial de la vivienda, la dotación de los nuevos conjuntos con equipa- 
mientos mínimos, incorporando además de manera reciente, la idea de plan maestro ${ }^{5}$ como herramienta de gestión y de diseño urbano. Como un hecho que afecta directamente a la vivienda en altura como tipología, el trabajo que se ha desarrollado en torno a la formulación de "planes de habilitación social" PHS es una decisión que comienza a dar cuenta del reconocimiento por parte del Estado respecto del impacto directo que tiene sobre la producción de la vivienda social en altura preparar a los vecinos para la vida en comunidad. Como una herramienta de organización y capacitación, el PHS "forma parte del proyecto habitacional desde [...] la organización de la demanda, hasta [...] la instalación de las familias en sus nuevas viviendas" con el objetivo de "que las familias postulantes desarrollen las habilidades necesarias para tener y administrar su vivienda propia, asumirla como un patrimonio familiar, insertarse en barrios y redes sociales que les permitan mejorar su calidad de vida, planificar y llevar a cabo (posteriores) proyectos de ampliación y mejoramiento de su vivienda y entorno" (MINVU, 2008:9).

Sin embargo, si bien todos estos cambios han determinado una preocupación por la vivienda social en altura desde su origen, considerando una mayor superficie y calidad de los departamentos, una nueva imagen arquitectónica (Figura 10), la educación respecto a la vida en comunidad, así como la obligatoriedad de ser inscritos en el conservador de bienes raíces, queda pendiente aún la intención de configurar morfológicamente las copropiedades desde diseño del proyecto residencial.

Por otro lado, en una nueva línea de acción, que busca atender el significativo deterioro del parque habitacional ya construido por las propias políticas públicas, a partir de ese momento se comienzan a diseñar e implementar nuevos programas de mejoramiento con metodologías y herramientas especificas a la intervención en copropiedades. Esta temática también es reconocida por la PNDU (2014), planteando la necesidad de revertir las actuales situaciones de segregación urbana por medio de iniciativas como el "apoyo a los condominios de viviendas sociales cuyos residentes, por diversas causas, no tienen la posibilidad de mantener apropiadamente sus bienes comunes", entre otras.

\section{De la Ley de Venta por Pisos a la Ley de Copropiedad Inmobiliaria:}

Conscientes de la relación directa entre el deterioro y la mantención de los bienes comunes en la tipología de vivienda colectiva, un hecho significativo, que ha venido a instalar la importancia de la copropiedad, es que después de 60 años de vigencia de la Ley de Venta por Pisos de 1937, en el año 1997, se implementa la Ley de Copropiedad Inmobiliaria 19.537 con el objetivo de

"contar con una legislación moderna y orgánica que responda a las necesidades de estas comunidades, facilite la realización de inversiones de gran envergadura, permita la renovación del patrimonio urbano y flexibilice la administración de los grandes conjuntos habitacionales, sin que se generen problemas de convivencia y administración" (MINVU, 1997).

Por medio de la formulación de planes maestros, a partir del año 2016 se han comenzado a impulsar los Planes Urbano-Habitacionales, con el objetivo "construir barrios integrados socialmente, dotados de bienes públicos urbanos de calidad, incorporando criterios de sustentabilidad y pertinencia de tal forma de evitar la segregación urbana" (Minvu, 2018). 
De este modo, con el desafío de generar mejores entornos y condiciones adecuadas de convivencia, seguridad y calidad de vida en comunidad, la ley establece un nuevo marco regulatorio que busca favorecer la formalización ${ }^{6}$, reglamentación, mantención administración de las copropiedades, tanto para nuevos proyectos como en el caso de tantos conjuntos ya construidos que presentan indefiniciones y desconocimiento respecto de qué es, cómo funcionan o hasta dónde llegan territorialmente sus copropiedades.

Sin embargo, uno de los elementos más relevantes en cuanto a la evolución del enfoque de la política pública, es que se incorpora un capítulo especial sobre copropiedades de vivienda social, a partir del cual entre otros aspectos, se plantea la posibilidad de exención de los pagos que demande la organización y cumplimiento de los requisitos legales en los procesos de formalización, desarrollando programas de capacitación para la administración de la copropiedad, así como orientaciones para postular a los distintos programas de financiamiento público. Un hecho significativo en esta línea es la instalación del concepto de "Condominio social" como nueva semántica en la política pública, reconociendo así la complejidad de la vivienda en altura como tipología y la necesidad de apoyar desde el Estado en el mantenimiento, ampliación o mejoramiento de los bienes comunes a través de la inversión pública.

Por otra parte, la luz de los aprendizajes que ha significado la implementación y evolución de los diversos programas de mejoramiento de las copropiedades, interesante dar cuenta cómo la propia Ley se ha ido adaptando a los requerimientos que exige la copropiedad en conjuntos de vivienda social. Uno que destaca en este sentido es el cambio realizado al cuerpo legal de la Ley diciembre de 2017, con el objetivo de "promover la organización social, facilitar la toma de decisiones y aclarar los roles al interior de las copropiedades" (Ley 20.168 modificación, dic. 2017).

En consecuencia, resulta interesante observar que, si bien aún no se ha incorporado la mirada físico espacial como una dimensión fundamental del proyecto residencial en torno a la configuración de las copropiedades, se evidencia, al menos, un esfuerzo por reorientar la política habitacional, desde un enfoque exclusivamente económico hacia una esfera comunitaria, que reconoce la necesidad de fortalecer la organización social al interior de los conjuntos.

\section{Copropiedad: presencia silenciosa no integrada al proyecto residencial}

La identificación de los distintos periodos analizados por el estudio, indagando cómo ha evolucionado la noción de copropiedad respecto del proyecto residencial en altura impulsado por la política habitacional chilena y sus efectos en la convivencia vecinal, permiten comprender las diversas problemáticas, potencialidades y desafíos de futuro que enfrenta la tipología en la materia.

Si bien la copropiedad, asociada a la administración y mantención de los bienes comunes, y la vivienda pública en altura nacen prácticamente juntas, a partir del análisis, es posible constatar

Se entiende por formalización el proceso que dota a la copropiedad de un reglamento, la constitución de un Comité de Administración, la subdivisión del condominio y otros de similar naturaleza. 
cómo la relación entre ambas se ha establecido posterior a la existencia del proyecto, cuando los habitantes ya están presentes en ellas. Es decir que, aunque el concepto de copropiedad conlleva el valor de la vida comunitaria, el diseño proyectual de los conjuntos se establece de manera aislada sin considerar el marco normativo existente en la materia y, menos aún, recoger las distintas formas de uso, apropiación, modos de habitar e interactuar de los futuros habitantes.

Se confirma de este modo, cómo la evolución y consolidación del proyecto residencial colectivo en Chile ha estado definido predominantemente por aspectos económicos como son la eficiencia en el uso del suelo, el número de unidades habitacionales o la regulación de los estándares de construcción, lo que ha llevado a la progresiva racionalización de los conjuntos, invisibilizando poco a poco la noción de copropiedad en el tiempo.

Es posible observar en este sentido, cómo los distintos contextos históricos e influencias proyectuales, van sentando los énfasis de la política pública en cada período, estableciendo el marco normativo para la construcción habitacional, lo que determina la transformación morfológica, tipológica y espacial que irá experimentando la vivienda en altura, y con ella las distintas formas de apropiación, organización y convivencia vecinal. De este modo, aunque la copropiedad como dimensión nunca ha sido incorporada de manera simultánea y real en el proyecto residencial, es posible concluir que aquellos conjuntos diseñados bajo la mirada de integralidad propuesta por el movimiento moderno logran configurar un mejor sentido de lo colectivo, respecto de aquellos construidos bajo un enfoque exclusivamente cuantitativo y mercantilista, donde la desconexión entre el proyecto y los modos de habitar han terminado por generar diversas y complejas relaciones vecinales.

Podemos concluir entonces, que, si el proyecto residencial no configura desde su origen unidades de carácter colectivo, de adecuado tamaño y morfología, espacialmente reconocibles por sus habitantes y con una clara distinción de la propiedad privada respecto de los bienes comunes, entre otros aspectos, la aplicabilidad de la copropiedad como herramienta de regulación y convivencia poco puede hacer. Así también, aunque muchas de las problemáticas de la vivienda social en altura están asociadas a la dimensión física y el paso del tiempo, desde una perspectiva social, el origen de las comunidades, la presencia y concentración de pobreza, o el nivel de información de las familias respecto a la vida en copropiedad, determinan su agudización, condicionando finalmente la capacidad de organización, administración y mantención de los bienes comunes e induciendo más aún el deterioro y el conflicto vecinal.

Finalmente, si bien en la actualidad podemos observar un significativo reconocimiento de la noción copropiedad por parte de la política pública, estableciendo un vínculo entre la dimensión social y el sentido de lo colectivo que conlleva la vida en comunidad, aún queda pendiente el desafío de establecer un vínculo con la dimensión proyectual, indagando en la configuración de espacios residenciales adecuados que promuevan el conocimiento, la convivencia y la organización vecinal, como propuestas que favorecerán la sostenibilidad del proyecto residencial en altura.

\section{Conclusiones}

Marcados por el aumento de la población urbana y necesidad de enfrentar el crecimiento de las ciudades desde una adecuada densificación, la vivienda colectiva como tipología ha llegado para quedarse. 
Sin embargo, en el contexto de una sociedad caracterizada por una alta individualización, con miras a desarrollar propuestas residenciales que apunten a su propia sostenibilidad en el tiempo, con mejores niveles de habitabilidad y satisfacción residencial, se evidencia la necesidad de repensar el significado que adquiere lo colectivo especialmente en comunidades marcadas por diversas problemáticas sociales y múltiples demandas espaciales. De aquí que, en un nuevo escenario, político, social y económico para las políticas públicas, pase a ser fundamental relevar la importancia de comenzar a pensar el proyecto residencial colectivo desde un enfoque multidimensional, que establezca una indisoluble relación entre diseño (dimensión física), formas de convivencia vecinal (dimensión social) y régimen de copropiedad (dimensión legal):

Aparecen así diversas interrogantes respecto de cuál es el adecuado tamaño, altura, densidad y morfología de las copropiedades y del conjunto habitacional, así como en relación a cómo son las prácticas cotidianas y formas de convivencia colectiva de los habitantes. De este modo, insistiendo en el impostergable requerimiento de incorporar a las familias en el diseño de sus conjuntos, se instala el desafío de comenzar a indagar en nuevos diseños arquitectónicos que configuren adecuadas unidades morfológicas de administración (copropiedad) y convivencia vecinal, las que, por medio de un adecuado tamaño y configuración espacial, permitan el reconocimiento entre vecinos, así como el cuidado y mantención de un territorio colectivo, con el cual los habitantes se identifican y reconocen como propio.

Por otra parte, reconociendo que en la actualidad existen diversos requerimientos habitacionales, determinados por las necesidades espaciales de cada núcleo familiar como es el número y tipo de integrantes, la presencia de discapacidad o la que la vivienda incorpore un espacio laboral, taller, comercio, etc., el estudio en relación a la combinación de diversos tipos de viviendas y/o departamentos, con distintas superficies y programas en una misma unidad arquitectónica, plantea el desafío de investigar en torno a lo que ha sido denominado como "tipologías residenciales compuestas" (Bustos, 2005:310), escapando así a la repetición de un único tipo habitacional. Indagar sobre este nuevo tipo de arquitectura, además de favorecer el grano y diversidad del proyecto residencial, rompiendo la homogeneidad del paisaje urbano de los sectores más vulnerables, podrá colaborar también -frente al nuevo desafío de generar un parque habitacional en arriendo-, en la dotación de nuevas unidades habitacionales, permitiendo la movilidad de las familias dependiendo sus requerimientos en un mismo barrio o copropiedad.

Finalmente, están también aquellas variables referidas a la posterior consolidación de los entornos urbanos y los mecanismos para el adecuado funcionamiento de la copropiedad por parte de sus habitantes, dentro de las que ya podemos identificar algunos avances. Sin embargo, entendiendo la vivienda pública como una problemática de carácter integral, queda aún pendiente un nuevo desafío que pone énfasis en la integración urbana del proyecto residencial en el contexto de la ciudad, apuntando a mejorar no solo la calidad y diversidad habitacional de los conjuntos, sino que también de los entornos barriales y urbanos.

\section{Bibliografía}

AGUIRRE, M. La arquitectura moderna en Chile (1907-1942). Revistas de arquitectura y estrategia gremial. Santiago: Editorial Universitaria, 2011. 
BALLÉN, S. Vivienda social en altura: tipologías urbanas y directrices de producción en Bogotá. $1^{a}$ ed. México: Instituto del Fondo Nacional de la Vivienda para los Trabajadores (Infonavit); Universidad Autónoma del Estado de México, Facultad de Ciencias Políticas y Sociales, 2010.

BRAVO, L.; MARTíNEZ, C. Chile: 50 años de vivienda social, 1943-1993. Facultad de Arquitectura, Universidad de Valparaíso, 1993.

BUSTOS, M. El proyecto residencial en baja altura como modelo de crecimiento urbano: Santiago de Chile y su política de vivienda en el último cuarto de siglo. Tesis Doctoral. Barcelona, Departamento de Urbanismo y Ordenación Territorial. Universidad Politécnica de Cataluña, 2005.

BUSTOS, M. Los conjuntos colectivos como resultado de la formación de una concepción de vivienda pública (1936-1952). Las tipologías en altura y el aumento de la construcción habitacional. En Vivienda Social en Copropiedad. Memoria de tipologías en Condominios Sociales. Capítulo 2. Minvu. Santiago de Chile, 2014a. p. 67-150.

BUSTOS, M. La Racionalización de la Producción habitacional. La formación de las tipologías colectivas como resultado del marco Normativo. En Vivienda Social en Copropiedad. Memoria de Tipologías en Condominios Sociales. Capítulo 3. Minvu. Santiago de Chile, 2014b. p.153-298

DE MATTOS, C. Santiago de Chile de cara a la globalización. ¿Otra ciudad? Revista Sociología Política, Curitiba, 2002, Nº19, p. 31-54.

DELGADO, M. Lo común y lo colectivo. El espacio público como espacio de y para la comunicación. Medialab Prado. 2008, p. 1-11.

DUCCI, M. Chile: El lado oscuro de una política de vivienda exitosa. Revista de estudios urbanos regionales EURE, 1997, 23(69), p. 99-115.

GARCÉS, E. Las Ciudades del Cobre: Sewell, Chuquicamata, Potrerillos, El Salvador, San Lorenzo, Pabellón Inca, Los Pelambres. Santiago. Ediciones Universidad Católica de Chile, 2007.

HARAMOTO, E. Un enfoque cualitativo del entorno inmediato a la vivienda social. Boletín INVI N ${ }^{\circ}$ 5. Facultad de Arquitectura y Urbanismo. Universidad de Chile. 1990, p. 20-29.

HIDALGO, R. La vivienda social en Chile y la construcción del espacio urbano en el Santiago del siglo XX. Santiago de Chile: Pontificia Universidad Católica de Chile, 2005.

HIDALGO, R., ZUNINO, H. y ÁLVAREZ, L. El emplazamiento periférico de la vivienda social en el área metropolitana de Santiago de Chile: consecuencias socio espaciales y sugerencias para modificar los criterios actuales de localización. Revista Scripta Nova, 2007, 11, p. 245-27.

HERNANDEZ, C. Reseña de "La naturaleza del espacio" de Milton Santos. Revista Economía, Sociedad y Territorio, 2001, vol. III, núm. 10, p. 379-385. 
MARTí, C. Las Formas de la Residencia en la Ciudad Moderna. Col-lecció d' Arquitectura Edicions UPC, Barcelona, 2000.

MINISTERIO DE JUSTICIA. Ley num. 6,071. 1937. Consultado en: https://www.leychile.cl/Navegar/?idNorma=256753

MINISTERIO DE VIVIENDA Y URBANISMO. Memoria Anual 1984. Santiago de Chile, 1984.

MINISTERIO DE VIVIENDA Y URBANISMO. Ley 19537. Sobre copropiedad inmobiliaria. En: https:// www.leychile.cl/Navegar?idNorma=81505, 1997.

MINISTERIO DE VIVIENDA Y URBANISMO. Política habitacional de mejoramiento de la calidad e integración social. Política habitacional. Santiago: MINVU. 2006.

MINISTERIO DE VIVIENDA Y URBANISMO. Chile, un siglo de políticas en vivienda y barrio. Santiago, Ministerio de Vivienda y Urbanismo. 2007.

MINISTERIO DE VIVIENDA Y URBANISMO. Manual para el diseño y ejecución de Planes de Habilitación Social. Fondo Solidario de Vivienda. SERVIU, 2008.

MINISTERIO DE VIVIENDA Y URBANISMO. Planes Urbano Habitacionales PUH, Minvu 2018. En: http://minvuhistorico.minvu.cl/opensite_20180329142331.aspx

MINISTERIO DE VIVIENDA Y URBANISMO. Catastro Nacional de Condominios Sociales. Área de Estudios. Secretaría Ejecutiva Recuperación de Barrios. MINVU, 2014.

MÚNERA, M.; SÁNCHEZ, L. Construcción social de hábitat: Reflexiones sobre políticas de vivienda en Colombia. En Instituto de la Ciudad FLACSO Ecuador CLACSO (Eds.), Políticas de empleo y vivienda en Sudamérica. Quito, 2012, p. 75-93

Organización para la Cooperación y el Desarrollo Económico. OECD Urban Policy Reviews, Chile 2013, OECD Publishing. [Online] Descargable en: http://www.oecd-ilibrary.org/urban-rural-and-regional-development/oecd-urban-policy-reviews-chile-2013_9789264191808-en

POLÍTICA NACIONAL DE DESARROLLO URBANO. Hacia una nueva Política Urbana para Chile. Consejo Nacional de Desarrollo Urbano. 2014, Vol. 4. p. 23-25

RODRÍGUEZ, A.; ICAZA, A. Procesos de expulsión de habitantes de bajos ingresos del centro de Santiago, 1981-1990. Proposiciones, 1993, p. 138-172.

RODRÍGUEZ, A.; SUGRANYES, A. El problema de vivienda de los con techo. En Rodríguez A. y Sugranyes A. (Eds.), Los con techo. Un desafío para la política de vivienda social. Ediciones Sur Profesionales. 2005, p. 80. 
RAPOSO, A. La vivienda social de la CORVI: un otro patrimonio. Revista INVI, 1999, 14 (37): p. 41-73. Consultado en: http://revistainvi.uchile.cl/index.php/INVI/article/view/247

RAPOSO, A. Estado, Ethos Social y Política de Vivienda. En RAPOSO, A. Espacio Urbano e ideología. El paradigma de la corporación de la Vivienda en la Arquitectura Habitacional Chilena. 19531976. Centro de estudios de la Vivienda. Universidad Central. 2001, p. 81-149.

SABATINI, F.; SALCEDO, R.; GÓMEZ, J.; SILVA, R.; TREBILCOCK, M. "Microgeografías de la segregación: estigma, xenofobia y adolescencia urbana". En: SABATINI, F.; WORMALD, G. y RASSE, A (eds.), Segregación de la vivienda social: ocho conjuntos en Santiago, Concepción y Talca. Santiago de Chile: Colección Estudios Urbanos UC, 2013, p. 34-66.

SALCEDO, R. El último campamento: Mudándose del asentamiento ilegal a la vivienda propia subsidiada en Chile (2010). En ERRAZURIZ, T. y GREENE, R (Eds.), Salcedo. Editorial Bifurcaciones. Talca, 2017. p. 153-171.

SALCEDO, R.; HERMANSEN, P. RASSE, A. Habitando el gueto. Estrategias para sobrevivir un espacio público deteriorado: El caso de Bajos de Mena en Santiago, Chile. En ERRAZURIZ, T. y GRENNE, R. (Eds.), Salcedo, Editorial Bifurcaciones. Talca, 2017. p. 175-191.

SALCEDO, R. RASSE, A y CORTÉS, A. Del Proyecto colectivo al aislamiento: la desaparición de la noción de barrio. En SABATINI, F.; WORMANLD, G. y RASSE, A. Segregación de la Vivienda Social: Ocho conjuntos en Santiago, Concepción y Talca. Santiago: Colección Estudios urbanos UC. 2013, p. 69-95.

SEGOVIA, O. Habitar en conjuntos de vivienda social: ¿Cómo construir identidad, confianza y participación social? En RODRÍGUEZ, A. y SUGRANYES A. (Eds.), Los con Techo: un desafío para la vivienda social. Santiago de Chile, Ediciones Sur Profesionales. 2005, p.79-97.

SUGRANYES, A. La política habitacional en Chile, 1980-2000: un éxito liberal para dar techo a los pobres. En RODRÍGUEZ, A. y SUGRANYES A. (Eds.), Los con Techo: un desafío para la vivienda social. (pp.30). Santiago de Chile, Ediciones Sur Profesionales. 2005, p. 23-57.

VALENZUELA, L. La Caja de Habitación Popular: El Rostro Cambiante de la Vivienda en Chile 19361952. En CASTILLO, M. e HIDALGO, R. (Eds.) Cien Años de Política de Vivienda en Chile. Santiago: Facultad de Arquitectura y Diseño Universidad Nacional Andrés Bello - Instituto de Geografía Pontificia Universidad de Católica de Chile. 2007, p. 65-84

YORI, C. La construcción social del Hábitat. Como estrategia de integración social, sustentabilidad urbana y seguridad ciudadana. Universidad piloto de Colombia, 2015. WIEDENSON, D. Utopian Aspects of Tony Garnier's Cité Industrialle. The Journal of the Society of Architectural Historians, 1960, Vol.19, N 1, p. 16-24. 